\title{
Anti-Obesity Efficacy of Roots of Stereospermum suaveolens in High Fat-Induced Obese Rats
}

\author{
Sai Sruthi Kaveripakam*, Sreedevi Adikay, Gandhimathi Retnasamy \\ Division of Pharmaceutical Chemistry, Institute of Pharmaceutical Technology, Sri Padmavathi Mahila Visvavidyalayam, Tirupati, Andhra Pradesh, INDIA.
}

\begin{abstract}
Objective: The present study was designed to evaluate the anti-obesity efficacy of ethanol extract of roots of Stereospermum suaveolens on high fat fed obese rats. Methodology: Ethanol extract of roots was prepared by hot extraction method and preliminary phytochemical studies had been conducted. Obesity was induced in Wistar rats by administration of high fat diet for 40 days. Anti-obesity effect was screened by oral administration of extract at two different dose levels i.e. 200 and $400 \mathrm{mg} / \mathrm{kg}$ bd wt. along with high fat diet for 40 days. Orlistat at a dose of $50 \mathrm{mg} / \mathrm{kg}$.bd.wt was used as standard drug control. The anti-obesity activity is estimated in terms of body weight gain, food intake, Lee-index, Serum triglycerides (TG), Total cholesterol (TC), LDL cholesterol (LDL-C), HDL cholesterol (HDL-C), VLDL cholesterol (VLDL-C), blood glucose (BG), atherogenic index, coronary risk index and organ and fat pad weights. Histological studies had been carried out for hepatic tissue. Results: Administration of high fat diet for 40 successive days significantly increased the body weight, food intake, organ and fat pad weights, Lee index, atherogenic index, coronary risk
\end{abstract}

index, TG, TC, LDL, VLDL, BG and decreased HDL levels in disease control animals. Animals administered with extract for 40 successive days along with high fat diet reversed the effects induced by high fat in dose dependent manner. Conclusion: The present study depicts that the ethanol extract of roots of Stereospermum suaveolens have a promising anti-obesity efficacy.

Key words: Anti-obesity, High fat diet, Orlistat, Stereospermum suaveolens.

Correspondence :

Sai Sruthi Kaveripakam,

Research scholar, Institute of Pharmaceutical technology, Sri Padmavati Mahila Visvavidyalayam, Tirupati- 517502, Andhra Pradesh, INDIA.

Email: sruthisai7@gmil.com*; sridevitirupati@rediffmail.com, saardhana007@gmail.com

DOI: 10.5530/jyp.2017.9.46

\section{INTRODUCTION}

Obesity is a disarray of energy balance and fundamentally considered as a disorder of lipid metabolism. ${ }^{1}$ It is characterized by excessive fat deposition in adipose tissue and other internal organs like liver, heart, skeletal muscle and pancreatic islet. In the present scenario obesity remains as a major global public health problem because of its prevalence, cutting across all age groups, sex and race. ${ }^{2}$ Worldwide about 1.9 million adults are overweight and 600 million of them are clinically obese. ${ }^{3}$

Obesity is caused by altered lipid metabolic processes including lipogenesis and lipolysis. It is characterized by enlarged fat mass and lipid concentration in blood. ${ }^{4}$ Obesity is also associated with many ailments like diabetes mellitus, hypertension, osteoarthritis, cancers and renal impairment. ${ }^{5}$ As prevalence and severity of obesity and associated co-morbidities are increasing there is a dire need to develop safe and effective drugs for its management. Only a single drug named Orlistat was currently approved by USFDA for long term obesity treatment. But it has undesirable side effects like dyspepsia, nephrotoxicity, flatulence, respiratory infection, oily stools, abdominal pain, menstrual and psychiatric disorders. ${ }^{6}$ Thus, discovering new targets and safe therapeutic agents is a focal point for combating this epidemic.

Phytotherapy, more than preference to synthetic drugs for obesity treatment is considered as a complementary approach for preventing and treating disease. At present, the potential of natural products for the treatment of obesity has been explored and it can be an excellent alternative for the development of safe anti-obesity agents. ${ }^{7}$ A large number of Indigenous drugs have been claimed to possess anti-obesity effect in the Indian system of medicine. Many medicinal plants like Allium sativum, Argyreia nervosa, Nelumbo nucifera, Sida rhomboidea, Camellia sinensis are reported to have anti-obesity effect in different animal models. ${ }^{8,9}$ Still a considerable number of plants claimed to possess anti-obesity effect yet to be scientifically explored.

Stereospermum suaveolens belonging to the family Bignoniaceae, popularly known as padhri, is a large deciduous tree found throughout the moist parts of India. ${ }^{10}$ The various parts of the plant are used traditionally for the treatment of various ailments. Traditionally root is used in the remedies of diseases like in "kapha", and "amlapitta", inflammations, heating, dyspnoea, body ache, vomiting, eructation, piles, acidity, diarrhoea, gonorrhoea, loss of taste, liver disorders, malaria and other fevers. Root is also useful in excessive thirst, cough, asthma and weight gain. ${ }^{11}$ Previous scientific studies evidenced that plant possess anti-inflammatory, anticancer, hepatoprotective, antihyperglycemic, antioxidant activities. ${ }^{12}$ But the utility of the roots of this plant for treatment of obesity has not been scientifically evaluated. Hence, the aim of the present study is to evaluate the anti-obesity efficacy of ethanol extract of roots of Stereospermum suaveolens (EESS) in high fat diet (HFD) -induced obese rats.

\section{MATERIALS AND METHODS}

Collection and authentication of plant material: The roots of Stereospermum suaveolens were collected from Tirumala hills, Chittor district of Andhra Pradesh. The plant was authenticated by Botanist Dr. Madhavachetty, Herbarium keeper, Department of botany, Sri Venkateswara University, Tirupati, India and a specimen (No. 1587) has been deposited in Department of Botany, Sri Venkateswara University, Tirupati, India. Roots were washed, shade dried and powdered in Wiley mill. 
Preparation of extract: The root powder was defatted with petroleum ether $\left(60-80^{\circ} \mathrm{C}\right)$. The defatted marc was air-dried and macerated with ethanol for $24 \mathrm{~h}$. Macerated material was refluxed for $3 \mathrm{~h}$., then filtered and subjected to distillation under reduced pressure.

Preliminary phytochemical studies: Preliminary phytochemical studies had been performed using standard procedures to identify the presence of alkaloids, glycosides, flavonoids, saponins, phenolic compounds, tannins, etc. ${ }^{13}$

Experimental animals: Wistar strain Albino rats weighing 150-180gm were selected for study. The animals were maintained in a well-ventilated room with 12:12 hour light/dark cycle in polypropylene cages. They had free access to standard pellets as basal diet and water ad libtum. The experimental protocol was approved by Institutional Animal Ethics Committee and carried out according to the guidelines of CPCSEA. (Registration No.: 1677/PO/a/12/CPCSEA).

Acute toxicity studies: Acute toxicity studies were carried out at a dose of EESS at $2000 \mathrm{mg} / \mathrm{kg}$ body weight according to the OECD 423 guidelines. The animals were kept under observation for 14 days. Any changes in body weights of the rat, changes in skin and fur, eyes and mucous membranes, salivation, nasal discharge, urination and behavioral (sedation, depression), neuromuscular (tremors, convulsions), cardiovascular changes, lethargy, sleep and coma were observed. ${ }^{14}$

\section{Induction of obesity}

The rodent feed was mixed to following ingredients to prepare high fat diet (HFD): Casein-20\%, D, L methionine- $0.3 \%$, corn starch-15\%, sucrose- $27.5 \%$, cellulose powder-5\%, mineral mixture-3.5\%, vitamin mixture- $1 \%$, choline bitartrate- $0.2 \%$, corn oil $-9.9 \%$, lard oil- $17.6 \% .{ }^{15}$ The high fat diet was prepared, dried, powdered and administered throughout the treatment period. Weight gain in animals was monitored regularly.

\section{Experimental design}

Rats were divided into five groups of six each:

Group-I : Normal control rats fed with standard chow diet and received vehicle for 40 days

Group-II: Obesity control rats fed with high fat diet (HFD) and received vehicle for 40 days

Group-III: Rats fed with HFD and treated with $200 \mathrm{mg} / \mathrm{kg}$ b.w of extract for 40 days

Group-IV: Rats fed with HFD and treated with $400 \mathrm{mg} / \mathrm{kg}$ b.w of extract for 40 days

Group-V: Rats fed with HFD and treated with orlistat (50mg/kg b.w) orally for 40 days

The food intake was measured daily and body weight was monitored weekly to assess the weight gain.

\section{Determination of adiposity level}

Adipocity level of animals can be measured through Lee index because it is highly correlated with the percentage of total body fat. ${ }^{16}$ The Lee's index is expressed as a cubic root of body weight in grams divided by the naso-anal length in millimeters multiplied by $10^{4}$.

\section{Estimation of lipid profile}

At the end of experiment i.e. on day 40 rats were fasted overnight and on the following day animals were sacrificed by cervical decapitation. Approximately $2 \mathrm{ml}$ of blood was collected by cardiac puncture. Blood glucose was estimated by Glucose-oxidase method. For estimation of lipid profile blood samples were centrifuged at $2500 \mathrm{rpm} / \mathrm{min}$ for 20 minutes to separate serum which was used for biochemical analysis. Serum total cholesterol \& HDL levels (CHOD-PAP method) and triglyceride levels (GPO-PAP method) were estimated using standard commercial kits. LDL cholesterol and VLDL cholesterol were calculated by Friedewald formula: VLDL-C = TG / 5; LDL-C = TC - (HDL-C + VLDL-C) ${ }^{17}$

\section{Assessment of Atherogenic and coronary risk index}

The atherogenic index and coronary risk index were calculated by formulae LDL-C/ HDL-C and TC/ HDL-C respectively. ${ }^{18}$

Organ and fat pad weights: The liver, kidney, spleen, heart and fat pads (mesenteric and perirenal fat pads) were dissected out, washed in ice cold saline and weighed.

Histopathological studies: Hepatic tissue was dissected from rats, and fixed in $10 \%$ neutral buffer formalin and processed to paraffin wax. Standard sections of $5 \mu \mathrm{m}$ were cut, stained with haematoxylin and eosin and were examined under light microscope.

\section{Statistical analysis}

The data was expressed as mean \pm standard error. Mean values between the groups was considered statistically significant $\mathrm{p}<0.05$ after analyzing by one way ANOVA and was compared using Tukey-Kramer multiple comparison tests.

\section{RESULTS}

Preliminary phytochemical studies: Preliminary phytochemical studies of EESS revealed the presence of flavanoids, saponins, phenolic compounds and tannins.

Acute toxicity studies: Animals received extract at a dose of $2000 \mathrm{mg} / \mathrm{kg}$ bd wt. had not shown any signs of toxicity and mortality was not observed up to day 14 .

\section{Assessment of anti-obesity activity Effect of EESS on lipid profile}

Effect of EESS on lipid profile in high fat diet induced obesity was represented in Table 1. Feeding high fat diet to group-II animals caused the elevations of serum TC and TG levels compared with that of animals which received normal diet. Animals treated with EESS (Group-III and IV) reduced TC and TG levels dose dependently when compared with Group-II animals. HDL levels were reduced significantly in Group-II animals when compared with normal animals (Group-I). Administration of EESS caused significant elevation of HDL levels in dose dependent passion when compared with HFD control group. In addition, HFD caused significant increase in LDL and VLDL levels in HFD control animals. Supplementation of EESS decreased significantly both LDL and VLDL levels when compared with the HFD control animals.

\section{Effect of EESS on blood glucose levels}

The results of blood glucose levels are mentioned in Table 1. There was a significant elevation in blood glucose levels in HFD control animals. Oral administration of EESS had significantly reduced blood glucose levels when compared with animals which received only HFD.

\section{Effect of EESS on body weight gain and food intake}

Effect of EESS on Body weight gain and food intake was shown in Table 2. A substantial increase in body weight had been noticed in HFD control group when compared with normal control animals. Oral supplementation of EESS significantly reduced the body weight gain dose dependently 
when compared with HFD control group. Food intake in EESS treated animals had also decreased when compared with HFD control animals.

\section{Effect of EESS on Lee-index, atherogenic index and coronary risk index}

Lee-index, atherogenic index and coronary risk index values were represented in Table 2. Feeding of high fat diet had increased Lee-index substantially compared to animals fed with normal diet. Administration of EESS for 40 Days along with HFD significantly decreased Lee-index in dose dependent manner. Atherogenic index and coronary risk index in animals treated with extract at both dose levels also decreased significantly when compared with HFD control.

\section{Effect of EESS on Organ and fat pad weights:}

Vivid differences in fat pad deposition levels were observed in terms of liver, perirenal and mesenteric fat pads amongst normal, high fat induced and EESS treated groups. The weights of liver, perirenal and mesenteric fat pad weights were markedly increase in HFD control animals. However administration of EESS at both dose levels reduced the weight of liver and fat pads in dose dependent manner. Weights of kidney, heart and spleen also increased in HFD control animals compared with normal animals. Supplementation of EESS decreased organ weights significantly when compared with HFD control group (Figure 1).

\section{Histological studies}

High fat diet consumption resulted in marked degeneration of hepatic tissue in HFD control animals. EESS administration considerably caused regeneration of hepatic tissues when compared with that of HFD control group (Figure 2).

\section{DISCUSSION}

Obesity is a medical condition in which abnormal or excessive fat accumulates in the body to the extent that the health is impaired. ${ }^{19}$ The global prevalence of obesity is increasing rapidly and hence there is a great demand for safer and long term effective drugs to treat this epidemic. ${ }^{20}$
A number of herbal extracts had been used in traditional medicine and scientifically explored for their anti-obesity activities. Stereospermum suaveolens is one such medicinal plant which was claimed to posssess anti-obesity effect in traditional medicine but still there is no corroborative scientific evidence. In current study, ethanol extract roots of Stereospermum suaveolens were evaluated for anti-obesity efficacy. Based on acute toxicity studies anti-obesity activity was screened at two dose levels i.e. lower dose (200mg/k bd wt) and higher dose (400mg/kg bd wt).

In earlier studies, it was reported that HFD induced obesity in rats was a suitable model since they bear close resemblance to human obesity. Like earlier studies in the present study also HFD was fed to rats to induce obesity. Our study results showed that dietary fat lipids had profound effect on the development of obesity in Albino rats and this is in concurrence with previous studies on HFD induced high body fat deposition and increased body weight. The raise in body weight might be due to increase energy intake leading to increased fat deposition and Lee-index of HFD fed animals was higher than 300 which can be classified as obese. ${ }^{21}$ As observed in earlier reports of different plant extracts like Argyreia nervosa, Nelumbo nucifera, Sida rhomboidea, animals which received EESS exhibited reduced body weight and decreased Lee index in dose- dependent manner. ${ }^{8,22,23}$ Further, reduce in food intake was also observed in EESS treated animals which may be due to hypophagic effect. $^{24}$

In concurrence with earlier reports, in present study also rats which received only HFD significantly elevated the serum concentrations of TC, TG, LDL-C and VLDL-C and decrease in HDL-C. The significant raise in lipid profile may be due to increase in both de-novo triglyceride and cholesterol synthesis and intestinal lipid uptake. ${ }^{25}$ Administration of EESS for 40 days along with HFD decreased the serum concentration of TC, TG, LDL-C and increased the concentration of HDL-C which may be due to lowering lipogenesis, enhancing lipolysis, suppressing appetite and reducing lipid absorption. ${ }^{24}$

Many reports have shown that long term exposure to HFD in experimental animals leads to hyperglycemia along with hyperlipidemia. In the current study HFD fed rats developed hyperglycemic state which may be because of defective insulin synthesis and decreased insulin efficiency.

Table:1 Effect of EESS supplementation on lipid profile and blood glucose

\begin{tabular}{ccccccc}
\hline Group & TC $(\mathbf{m g} / \mathrm{dl})$ & TG $(\mathrm{mg} / \mathrm{dl})$ & $\begin{array}{c}\text { HDL }(\mathrm{mg} / \\
\text { dl) }\end{array}$ & $\begin{array}{c}\text { LDL }(\mathrm{mg} / \\
\text { dl) }\end{array}$ & $\begin{array}{c}\text { VLDL }(\mathrm{mg} / \\
\text { dl) }\end{array}$ & BG (mg/dl) \\
\hline I & $59.67 \pm 1.12$ & $44.10 \pm 1.46$ & $45.83 \pm 1.04$ & $5.34 \pm 1.08$ & $8.80 \pm 0.29$ & $67.33 \pm 0.81$ \\
II & $176.7 \pm 2.97^{\mathrm{a}}$ & $162.8 \pm 1.99^{\mathrm{a}}$ & $26.67 \pm 0.95^{\mathrm{a}}$ & $117.4 \pm 3.9^{\mathrm{a}}$ & $32.57 \pm 0.39^{\mathrm{a}}$ & $152.3 \pm 2.18^{\mathrm{a}}$ \\
III & $88.33 \pm 2.74^{\mathrm{b}}$ & $81.67 \pm 2.34^{\mathrm{b}}$ & $33.37 \pm 0.88^{\mathrm{b}}$ & $37.97 \pm 3.34^{\mathrm{b}}$ & $16.33 \pm 0.47^{\mathrm{b}}$ & $98.33 \pm 2.10^{\mathrm{b}}$ \\
IV & $69.83 \pm 2.89^{\mathrm{b}}$ & $60.33 \pm 1.81^{\mathrm{b}}$ & $37.23 \pm 0.87^{\mathrm{b}}$ & $16.33 \pm 0.47^{\mathrm{b}}$ & $12.07 \pm 0.36^{\mathrm{b}}$ & $70.00 \pm 0.44^{\mathrm{b}}$ \\
V & $62.00 \pm 1.67^{\mathrm{b}}$ & $57.17 \pm 1.19^{\mathrm{b}}$ & $42.50 \pm 0.92^{\mathrm{b}}$ & $8.33 \pm 1.33^{\mathrm{b}}$ & $11.43 \pm 0.24^{\mathrm{b}}$ & $71.33 \pm 0.92^{\mathrm{b}}$ \\
\hline
\end{tabular}

Each value represents the Mean \pm S.E.M from 6 animals in each group. a: $\mathrm{p}<0.05$ when compared with Group-I; b: $\mathrm{p}<0.05$ when compared with Group-II.

Table: 2 Effect of EESS supplementation on body weight gain, food intake, Lee-index, atherogenic index and coronary risk index

\begin{tabular}{cccccc}
\hline Group & $\begin{array}{c}\text { Body weight } \\
\text { gain }(\mathbf{g})\end{array}$ & $\begin{array}{c}\text { Food intake } \\
(\mathbf{g})\end{array}$ & Lee-index & $\begin{array}{c}\text { Atherogenic } \\
\text { index }\end{array}$ & Coronary risk index \\
\hline I & $34.17 \pm 1.53$ & $15.42 \pm 0.19$ & $268.5 \pm 3.78$ & $0.15 \pm 0.01$ & $1.32 \pm 0.02$ \\
II & $110.0 \pm 3.60^{\mathrm{a}}$ & $20.42 \pm 0.64^{\mathrm{a}}$ & $320.0 \pm 4.42^{\mathrm{a}}$ & $4.45 \pm 0.29^{\mathrm{a}}$ & $6.67 \pm 0.33^{\mathrm{a}}$ \\
III & $52.50 \pm 2.50^{\mathrm{b}}$ & $17.64 \pm 0.11^{\mathrm{b}}$ & $303.5 \pm 2.88^{\mathrm{b}}$ & $1.15 \pm 0.11^{\mathrm{b}}$ & $2.65 \pm 0.09^{\mathrm{b}}$ \\
IV & $43.33 \pm 1.66^{\mathrm{b}}$ & $16.10 \pm 0.30^{\mathrm{b}}$ & $291.9 \pm 2.21^{\mathrm{b}}$ & $0.56 \pm 0.11^{\mathrm{b}}$ & $1.88 \pm 0.12^{\mathrm{b}}$ \\
V & $38.33 \pm 2.11^{\mathrm{b}}$ & $16.52 \pm 0.33^{\mathrm{b}}$ & $282.2 \pm 2.40^{\mathrm{b}}$ & $0.23 \pm 0.02^{\mathrm{b}}$ & $1.29 \pm 0.14^{\mathrm{b}}$ \\
\hline
\end{tabular}

Each value represents the Mean \pm S.E.M from 6 animals in each group. a: $\mathrm{p}<0.05$ when compared with Group-I. b: $\mathrm{p}<0.05$ when compared with Group-II. 


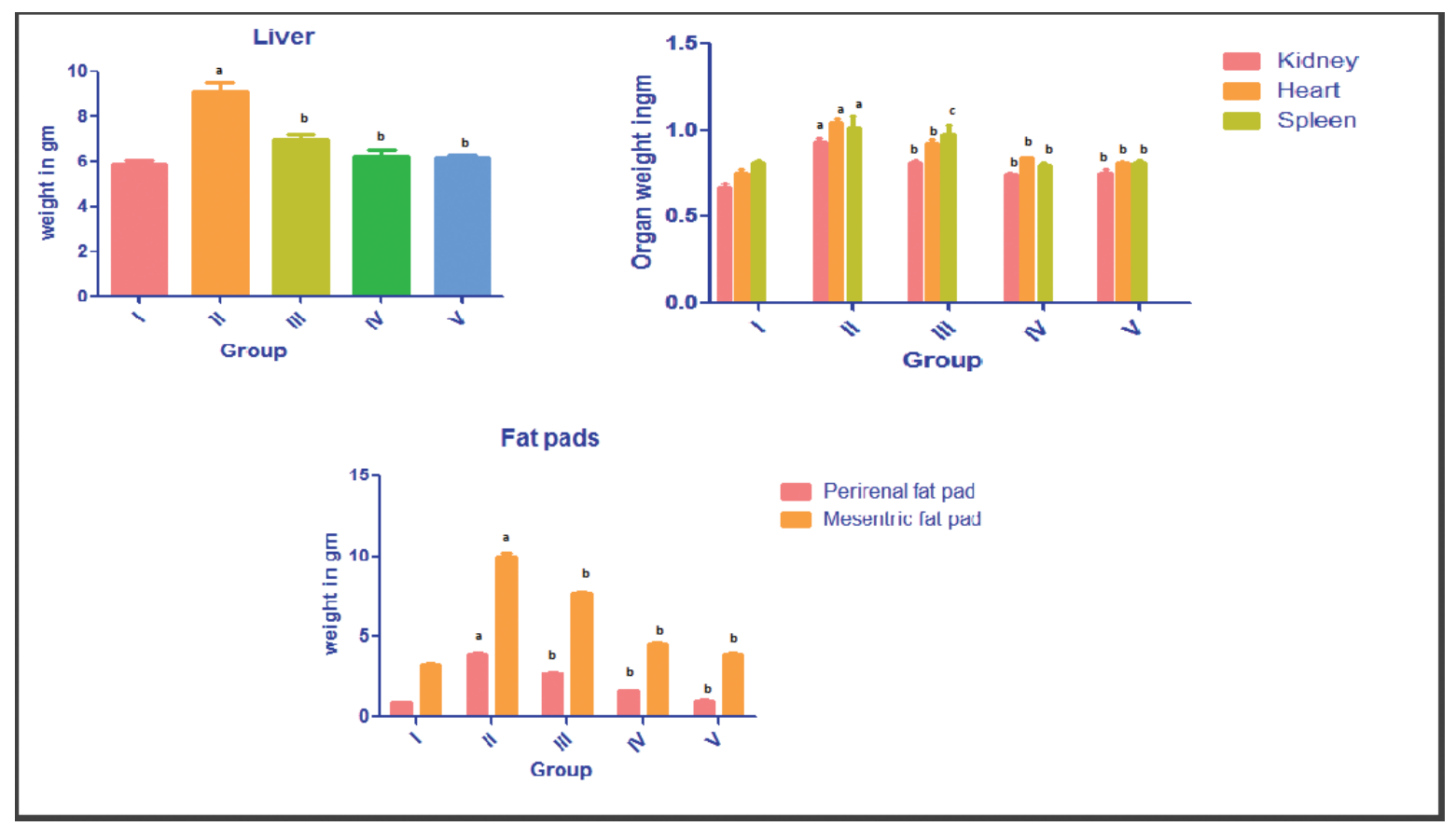

Figure: 1 Effect of EESS supplementation on organ weight and fat pads

Each value represents the Mean \pm S.E.M from 6 animals in each group. a: $p<0.05$ when compared with Group-I. b: $p<0.05$ when compared with Group-II. c: there is no significant difference when compared with Group-II.

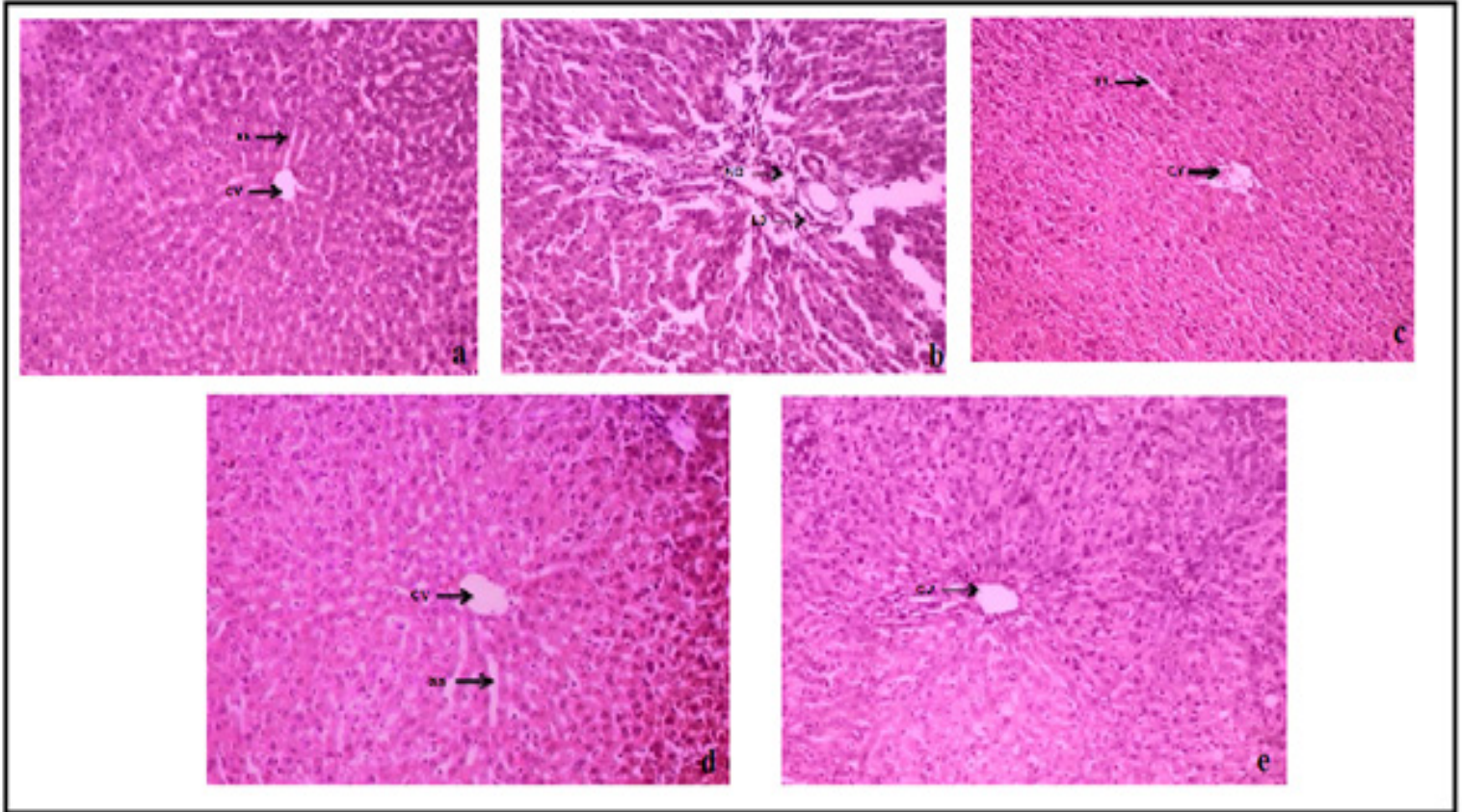

Figure: 2 Histopathological examination of hepatic tissue in experimental rats:

CV-Central Vein; SS-Sinusoids Space; DC-Degenerative Changes, NC-Necrotic Changes; LD-Lipid Deposits

Group-I - Normal control (normal hepatic tissue) (b) Group-II-HFD control (fatty liver tissue with more fat deposits and congestion) (c) Group-III-EESS 200mg/ $\mathrm{kg}$ bd wt (liver tissue showing regenerative changes) (d) Group-IV-EESS 400 mg/kg bd wt (liver tissue showing regenerative changes resembling normal control) (e) Group-V- Orlistat 50mg/kg bd wt. (The normal cyto-architecture of liver tissue indicates regenerative changes in the tissue).

However, supplementation of EESS normalized the glucose levels in dose dependent manner possibly by enhancing the secretion of insulin from the $\beta$-cells of the islets of pancreas or increasing the efficiency of insulin which facilitates the delivery of glucose from blood to target tissues. ${ }^{26}$ The atherogenic index and coronary risk index are strong and reliable indicators of whether or not cholesterol is deposited into tissues or meta- bolized and excreted. ${ }^{27}$ In current study, results are in good agreement with earlier reports i.e. rats fed with high fat diet, both atherogenic and coronary index had increased notably above the reference value (higher than 4 and 2.5 respectively). ${ }^{28}$ Administration of EESS in HFD-fed rats caused profound reduction in the atherogenic and coronary indices and thereby strongly confirmed the hypolipidemic effect of EESS. 
Huang et al., stated that obesity leads to fat accumulation, our current study results also supported earlier reports and exhibited significant raise in organ and fat pad weights in HFD control animals. ${ }^{29}$ EESS dose dependently decreased organ and fat pad weights which might be due mobilization of catabolism of lipids in adipose tissue. Further histopathological examination of hepatic tissue confirmed the anti-obesity activity of EESS as evident from the regenaration of hepatic tissue in EESS treated groups.

Upon preliminary phytochemical screening of EESS, it had revealed the presence of flavonoids, saponins, phenolic compounds and tannins. Earlier reports states that certain phytocomponents, particularly saponins, exhibit antihyperlipidaemic and hypocholesterolaemic actions by inhibiting or delaying intestinal lipid absorption via a resin-like action and by increasing enterohepatic excretion of cholesterol in the bile acid. ${ }^{30,31}$ Previous reports revealed that not only saponins but also flavonoids are also partially responsible for anti-obesity activity via lowering serum lipids by inhibiting the activity of HMG-CoA reductase and up-regulating the hepatic expression of peroxisome proliferators-alpha and gamma. ${ }^{32}$ Thus, the presence of hypolipidemic phytoconstituents like saponins, flavonoids and other phenolic compounds in the ethanol extract may be partially responsible for the anti-obesity efficacy of roots of Stereospermum suaveolens.

\section{CONCLUSION}

The results of the present study depicts that the ethanol extract of roots of Stereospermum suaveolens (EESS) have a promising role in therapy to high fat induced obesity. Further the findings of the present study provide scientific evidence for use of roots of Stereospermum suaveolens in traditional medicine for treating obesity.

\section{CONFLICT OF INTEREST}

No conflict of interest are declared.

\section{ABBREVIATION USED}

EESS: Ethanolic extract of Stereospermum suaveolens; HFD: High fat diet; TC: Total cholesterol; TG: Triglycerides; HDL: High density lipoproteins; LDL: Low density lipoproteins; VLDL: Very low density lipoproteins; b. w: body weight; g: Grams; mg/dl: Milligrams per decilitre.

\section{REFERENCES}

1. Birari RB., Gupta S, Mohan CG, Bhutani KK. Anti-obesity and lipid lowering effects of Glycyrrhiza chalcones: Experimental and computational studies. Phytomedicine. 2011; 18: 795-801.

2. World Health Organization, 1998. Obesity: preventing and managing the globa epidemic. Report of a WHO Consultation on obesity, WHO/NUT/NCD/98, Geneva, Switzerland, pp. 1-275.

3. Centre WM (2015) Obesity and overweigh. World Health Organization.

4. Devlin MJ, Yanovski SZ, Wilson GT. Obesity: what mental health professionals need to know. Am J Psychiatry. 2000; 157: 854-866.

5. Chang H P, Wang M L, Chan M H, Chiu Y S, \& Chen $Y H$. Antiobesity activities of indole-3-carbinol in high fat diet-induced obese mice. Nutrition. 2011; 27: 463-470.

6. Yun JW. Possible anti-obesity therapeutics from nature-a review. Phytochemistry. 2010; 71:1625-1641.

7. Birari R, Javia V, \& Bhutani K K. Antiobesity and lipid lowering effects of Murraya koenigii (L.) Spreng leaves extracts and mahanimbine on high fat diet induced obese rats. Fitoterapia. 2010; 81: 1129-1133

8. Patra S, Nithya S, Srinithya B, Meenakshi SM. Review of medicinal plants for antiobesity activity. J Transl med. 2015; 6: 3-21.

9. Patel DK, Patel KA, Patel UK, Thounaojam MC, Jadeja RN et al., Assessment of lipid lowering Effect of Sida rhomboidea.Roxb methanolic extract in experimentally induced hyperlipidemia J Young Pharm. 2009;1(3):233-238.

10. Kirtikar KR, Basu BD. Indian Medicinal Plants. Dehradun: International Book Distributors, 1988: pp. 1848-1849.

11. Srivastava N, Khatoon S, Rawat AKS, Rai V, Mehrotra V. Chromatographic estimation of p-coumaric acid and triacontanol in an Ayurvedic root drug Patala (Stereospermum suaveolens Roxb.). J Chromatogr Sci. 2009; 47: 936-939.

12. Meena K et al. Review on Stereospermum suaveolens (Roxb.) DC; a potential herb; Drug invent today. 2010; 2(5): 238-239.

13. Harborne J B, Phytochemical Methods. Chapman \& Hall: International Edition, Japan: Toppan Company Ltd; 1973 pp: 49-188.

14. Parasuraman S. Toxicological screening. J Pharmacol Pharmacother. $2011 ; 2(2): 74-79$

15. Vasselli JR, Weindruch R, Heymsfield SB, Pi-Sunyer FX, Boozer CN, Yi N, Wang C et al., Intentional weight loss reduced mortality rate in a rodent model of dietary obesity. Obes Res. 2005; 13: 693-702

16. Lee MO. Determination of the surface area of the white rat with its application to the expression of metabolic results. Am J Physiol. 1929; 89:24-31.

17. Friedewald WT, Levy $\mathrm{RI}$ and Fredrickson DS. Estimation of VLDL and LDLcholesterol in plasma, without use of the preparative ultracentrifuge. Clin Chem, 1972; 18: 499-502.

18. Abbott RD, Wilson PW, Kannel WB., Castelli WP. High density lipoproteincholesterol, total cholesterol screening and myocardial infarction. The Framingham Study. Arterosclerosis. 1988; 8: 207-211.

19. Saxena Y. Evaluation of dynamic function test in normal obese individuals. Indian J Physiol Pharmacol. 2008; 52(4): 375-382.

20. Yilmaz A, Suleyman H, Umudum Z, Sahin YN. The effect of adrenalectomy on leptin levels and some metabolic parameters in rats with diet-induced obesity. Biol Pharm Bull 2002; 25: 580—583.

21. Bernardis LL and Patterson BD. Correlation between 'Lee index' and carcass fat content in weanling and adult female rats with hypothalamic lesions. J Endocrinol. 1968; 40: 527- 528.

22. Haynes AC, Chapman H, Taylor C, Moore GBT, Cawthorne MA, Tadayyon M et al., John C. Clapham JC and Arch JR. Anorectic, thermogenic and anti-obesity activity of a selective orexin-1 receptor antagonist in ob/ob mice. Regul Peptides. 2002; 104: 153- 159.

23. Arch JR. The discovery of drugs for obesity, the metabolic effects of leptin and variable receptor pharmacology: perspectives from beta3-adrenoceptor agonists. Naunyn Schmiedebergs Arch Pharmacol, 2008; 378: 225-240.

24. Shivaprasad H N, Gopalakrishna S, Mariyanna B, Thekkoot M, Reddy R and Tippeswamy B S. 2014. Effect of Coleus forskohlii extract on cafeteria dietinduced obesity in rats. Pharmacog Res, 69: 41-45.

25. Irene PT, Ilias PD, Laskarina MK, George A, loannis SV, Alkisti P et al. Water Soluble Vitamin E Administration in Wistar Rats with Non-alcoholic Fatty Liver Disease. Open Cardiovasc Med J. 2012; 6: 88-97.

26. Kahn BB, Flier JS. Obesity and insulin resistance. J Clin Invest 2000; 106 : 473-481.

27. Hartog MGL, Feskens EJM., Hollman PCH, Katan MB, Kromhouy D. Dietary antioxidant flavonoids and risk of coronary heart disease: the Zutphen Elderly Study. Lancet 1993;342:1007-1011.

28. Adeneyea BAA, Adeyemi BOO, Agbajeb EO. Anti-obesity and antihyperlipidaemic effect of Hunteria umbellata seed extract in experimental hyperlipidaemia. J Ethnopharmacol. 2010; 130: 307-314.

29. Huang YW, Liu Y, Dushenkov S, Ho CT, Huang MT. Anti-obesity effects of epigallocatechin-3-gallate, orange peel extract, black tea extract, caffeine and their combinations in a mouse model. J Funct Foods, 2009; 1: 304-310.

30. Han LK, Kimura Y, Kawashima M, Takaku T, Taniyama T, Hayashi T, Zheng YN, Okuda H, 2001. Anti-obesity effects in rodents of dietary tea saponin, a lipase inhibitor. Int J Obes and Rel Metab Disord 25, 1459-1464.

31. YugaraniT, Tan BK, The M, Das NP. Effect of polyphenolic natural products on the lipid profiles of rats fed high-fat diets. Lipids. 1992 ; 27: 181-186.

32. Sharma B, Balomajumder C, Roy P. Hypoglycaemic and hypolipidaemic effects of flavonoid rich extract from Eugenia jambolana seeds on streptozotocin induced diabetic rats. Food Chem Toxicol. 2008; 46: 2376-2383.

Article History: Submission Date: 31-05-16; Received Date: 18-07-16; Acceptance Date: 21-08-16.

Cite this article: Kaveripakam S, Adikay S, Retnasamy G. Anti-Obesity Efficacy of Roots of Stereospermum suaveolens in High Fat-Induced Obese Rats. J Young Pharm. 2017;9(2):234-8. 